\title{
DEFICIÊNCIA HÍDRICA NO SOLO E SEU EFEITO SOBRE TRANSPIRAÇÃO, CRESCIMENTO E DESENVOLVIMENTO DE MUDAS DE DUAS ESPÉCIES DE EUCALIPTO(1)
}

\author{
Fabrina Bolzan Martins ${ }^{(2)}$, Nereu Augusto Streck ${ }^{(3)}$, Joel Cordeiro \\ da Silva ${ }^{(4)}$, Weslley Wilker Morais ${ }^{(5)}$, Felipe Susin ${ }^{(5)}$, Márcio Carlos \\ Navroski $^{(5)}$ \& Magnos Alan Vivian ${ }^{(5)}$
}

\begin{abstract}
RESUMO
A água é fundamental no metabolismo das plantas e uma redução na sua disponibilidade no solo pode afetar o crescimento, o desenvolvimento e a produtividade das culturas. O objetivo deste trabalho foi quantificar a influência do déficit hídrico no solo sobre a transpiração e sobre alguns parâmetros de crescimento (altura de planta e diâmetro do caule) e desenvolvimento (número de folhas acumuladas na haste principal), em mudas de Eucalyptus grandis (Hill ex Maiden) e Eucalyptus saligna (Smith). Para realização deste estudo, foi instalado um experimento em casa de vegetação, no Departamento de Fitotecnia da Universidade Federal de Santa Maria (Santa Maria, RS), que consistiu em duas épocas de semeadura, sendo a primeira em 1/10/2005 (E1) e a segunda em 12/5/2006 (E2). A água disponível, representada pela fração de água transpirável no solo (FATS), e os demais parâmetros foram medidos diariamente durante o período de imposição da deficiência hídrica. O início do decréscimo da transpiração, indicativo do fechamento dos estômatos, ocorreu quando a FATS foi de 0,9 (E2) e 0,7 (E1), para $E$. grandis, e de 0,7 , para $E$. saligna, em ambas as épocas, indicando que o fechamento estomático em resposta ao déficit hídrico no solo é mais rápido nessas espécies perenes do que em culturas agrícolas anuais. Os parâmetros de crescimento e desenvolvimento das mudas decresceram imediatamente após o
\end{abstract}

\footnotetext{
${ }^{(1)}$ Recebido para publicação em junho de 2007 e aprovado em janeiro de 2008.

(2) Doutoranda em Ciência Florestal, Departamento de Engenharia Florestal, Universidade Federal de Viçosa - UFV. Av. PH Rolfs s/n, CEP 36570-000 Viçosa (MG). Bolsista do CNPq. E-mail: fabrinabm@gmail.com

${ }^{(3)}$ Professor do Departamento de Fitotecnia, Universidade Federal de Santa Maria - UFSM. Av. Roraima 1000, CEP 97105-9000 Santa Maria (RS). E-mail: nstreck2@yahoo.com.br

(4) Professor do Centro Federal de Educação Tecnológica de São Vicente do Sul - CEFET/SVS. Rua Vinte de Setembro s/n, CEP 97420-000 São Vicente do Sul (RS). E-mail: jcsilva@cefetsvs.gov.br

(5) Alunos de Graduação em Engenharia Florestal, UFSM.
} 


\author{
início do déficit hídrico no solo, antes mesmo de ser a transpiração afetada pela \\ redução da água no solo.
}

Termos de indexação: fração de água transpirável no solo; estresse hídrico; Eucalyptus grandis; Eucalyptus saligna.

\title{
SUMMARY: SOIL WATER DEFCIT AFFECTING TRANSPIRATION, GROWTH AND DEVELOPMENT OF SEEDLINGS OF TWO EUCALYPTUS SPECIES
}

\begin{abstract}
Water is a critical component of plant metabolism, and a reduction in soil water availability may affect crop growth, development and yield. The objective of this study was to quantify the influence of soil water deficit on transpiration and on some growth (plant height and stem diameter) and development (main stem leaf number) parameters of Eucalyptus grandis (Hill ex Maiden) and E. saligna (Smith) seedlings. For this purpose, a greenhouse experiment was conducted at the Federal University of Santa Maria, RS, Brazil). The seedlings were planted on 10/1/2005 (PD1) and 5/12/2006 (PD2). Soil available water, expressed as the fraction of transpirable soil water (FTSW), and other parameters were measured daily during the period of water stress. Transpiration, which is an indicator of stomata closure, started to decrease at a FTSW of 0.9 (PD2) or 0.7 (PD1) in E. grandis, and at 0.7 for planting dates for E. saligna. These results suggest that stomata closure, in response to soil water deficit, occurs earlier in these two perennial species than in annual agricultural crops. Seedling growth and development parameter values began to decrease immediately after the onset of soil water deficit, even before transpiration was affected by the reduced soil water availability.
\end{abstract}

Index terms: fraction of transpirable soil water, water stress, Eucalyptus grandis, Eucalyptus saligna.

\section{INTRODUÇÃO}

A água é um recurso natural valioso e certamente o elemento mais importante para a vida dos animais e vegetais, pois é necessária à maioria das funções vitais, reações e rotas metabólicas (Carlesso \& Zimmermann, 2000). A água é o principal constituinte do tecido vegetal, representando $50 \%$ da massa fresca nas plantas lenhosas e cerca de 80 a $95 \%$ nas plantas herbáceas, sendo necessária como reagente no metabolismo vegetal, transporte e translocação de solutos, na turgescência celular, na abertura e fechamento dos estômatos e na penetração do sistema radicular (Taiz \& Zeiger, 2004). A água é ainda responsável pela forma e estrutura dos órgãos e essencial para o crescimento e desenvolvimento das culturas (Larcher, 2000), sejam elas anuais ou perenes (Carlesso \& Santos, 1999).

A redução da água disponível no solo para a planta influencia negativamente o seu crescimento e desenvolvimento (Sinclair \& Ludlow, 1986). Dessa forma, a produtividade agrícola e florestal é influenciada pela disponibilidade de água no solo. Levit (1980) salienta a importância de analisar as respostas das plantas e seus mecanismos de defesa ao déficit hídrico no solo. Entretanto, a quantificação do impacto da disponibilidade de água no solo sobre o crescimento e desenvolvimento vegetal tem recebido pouca atenção (Carlesso, 1995), especialmente nas espécies do gênero Eucalyptus (Kallarackal \& Somen, 1997).

A deficiência hídrica pode afetar o crescimento e desenvolvimento de espécies florestais em qualquer fase de seu ciclo (Façanha et al., 1983; Gonçalves \& Passos, 2000). No eucalipto, os sintomas da deficiência hídrica são mais visíveis e drásticos na fase de muda (Santarém et al., 1996; Jeller \& Perez, 2001; Silva et al., 2004). Dessa forma, o conhecimento das relações entre deficiência hídrica, crescimento e desenvolvimento nas espécies de Eucalyptus sp. durante a fase de muda assume particular importância, uma vez que, com o aumento da demanda por produtos de origem florestal, está aumentando a área plantada com espécies desse gênero, exigindo a produção de mudas de qualidade (Lima, 1993).

Existem vários índices que podem ser utilizados para expressar a quantidade de água no solo e, a partir deles, pode-se determinar-se o déficit hídrico no solo, como, por exemplo, quantidade total de água armazenada (QTA), capacidade de armazenamento de água disponível (CAD), fração de água disponível 
(FAD) e fração de água transpirável no solo (FATS). No conceito da FATS, assume-se que o conteúdo de água no solo utilizado pela planta para a transpiração varia entre o conteúdo de água no solo na capacidade de campo, quando é máxima, e o conteúdo de água no solo, quando a transpiração da planta é igual a $10 \%$ da máxima (Sinclair \& Ludlow, 1986). Este parece ser o conceito que mais se aproxima como indicador da quantidade real de água no solo que pode ser extraída pelas plantas para a transpiração (Santos \& Carlesso, 1998).

Para a determinação da FATS, são considerados dois estádios (Sinclair \& Ludlow, 1986; Muchow \& Sinclair, 1991; Bindi et al., 2005): o estádio I, quando a água está disponível livremente no solo e a planta não tem deficiência hídrica e sua condutância estomática e transpiração são máximas, ou seja, o conteúdo de água transpirável no solo não limita a condutância estomática e a transpiração; o estádio II, quando a água disponível no solo diminui e a planta diminui sua condutância estomática e transpiração para manter seu balanço hídrico e turgescência celular.

Utilizando o conceito de FATS, o conteúdo de água em que se inicia o fechamento estomático e, conseqüentemente, há redução da transpiração das plantas, foi determinado para várias espécies anuais agrícolas, como feijão caupi (Vigna unguiculata), feijão mungo (Vigna mungo) e guandu (Cajanus cajan) (Sinclair \& Ludlow, 1986), soja (Glycine max) (Sinclair, 1986), trigo (Triticum aestivum) (Amir \& Sinclair, 1991), milho (Zea mays) (Muchow \& Sinclair, 1991) e videira (Vitis vinifera) (Bindi et al., 2005). No entanto, poucos estudos têm investigado a transpiração e parâmetros de crescimento e desenvolvimento em resposta à deficiência hídrica em plantas lenhosas (Sinclair et al., 2005), especialmente em eucalipto (Eucalyptus spp.) (Kallarackal \& Somen, 1997), o que constituiu a motivação para realização deste trabalho.

O objetivo deste trabalho foi quantificar a influência do déficit hídrico no solo sobre a transpiração e sobre alguns parâmetros de crescimento e desenvolvimento em mudas de Eucalyptus grandis (Hill ex Maiden) e Eucalyptus saligna (Smith). Essas espécies foram escolhidas por representarem, respectivamente, $30 \%$ e $10 \%$ da área plantada com eucalipto no Estado do Rio Grande do Sul (ABRAF, 2006), além de serem objeto de controvérsia e debate de acordo com a eficiência no uso da água (Kallarackal \& Somen, 1997).

\section{MATERIAL E MÉTODOS}

Foi instalado um experimento em casa de vegetação na área experimental do Departamento de Fitotecnia da Universidade Federal de Santa Maria, Santa Maria, RS (latitude $29^{\circ} 43^{\prime} \mathrm{S}$, longitude $53^{\circ} 43^{\prime} \mathrm{W}$ e altitude de $95 \mathrm{~m}$ ). As sementes de Eucalyptus grandis e Eucalyptus saligna foram adquiridas da Estação Experimental de Silvicultura da Fundação Estadual de Pesquisa Agropecuária do RS (FEPAGRO), localizada no Distrito de Boca do Monte, Santa Maria, RS.

O delineamento experimental foi inteiramente casualizado em esquema fatorial com duas espécies de eucalipto (E. grandis e $E$. saligna), duas épocas de semeadura (E1, em 1/10/2005 e E2, em 12/5/2006), e dois tratamentos de suplementação de água (com irrigação - T1 e sem irrigação - T2) e 7 repetições. Cada repetição foi constituída de um vaso plástico preto de 8 litros preenchido com solo coletado no horizonte B de um Argissolo Vermelho-Amarelo distrófico típico. Os vasos foram dispostos sobre uma bancada de $70 \mathrm{~cm}$ de altura e espaçados de $50 \mathrm{~cm}$. Estes foram revestidos externamente com papel jornal, para reduzir a absorção da radiação solar e evitar o aumento da temperatura do substrato, o que constituiria uma fonte de erro experimental. A correção da acidez e da fertilidade do substrato foi realizada conforme recomendação técnica para as espécies utilizadas (SBCS/CQFS, 2004), a partir do resultado da análise do solo.

A emergência das plântulas ocorreu em 11/10/2005 e em 30/05/2006 para a semeadura na E1 e E2, respectivamente. Uma semana após a emergência, duas plantas por vaso foram marcadas com arame colorido. Foram realizados dois raleios nas plântulas, sendo o primeiro quando havia duas folhas visíveis na haste principal (HP) e o segundo quando havia quatro folhas visíveis na HP, deixando-se apenas as duas plantas marcadas por vaso, as quais foram usadas até o final do experimento. As brotações axilares foram removidas, à medida que foram aparecendo nas plantas, mantendo-se apenas a HP em crescimento.

Como parâmetros de crescimento, avaliaram-se a altura de planta (h), considerando-se o comprimento da HP do nível do solo até o ponto de crescimento apical, e o diâmetro do caule (d) ao nível do solo. Como parâmetro de desenvolvimento, contou-se o número de folhas emitidas ou acumuladas na haste principal (NF). Essas variáveis foram medidas a cada três dias até à aplicação da deficiência hídrica e, diariamente, após a aplicação desta. A contagem do NF foi iniciada quando havia, no mínimo, 2 folhas visíveis. As folhas foram consideradas visíveis quando tinham um comprimento do limbo de no mínimo 1,0 cm. A área foliar foi medida no primeiro e no último dia da aplicação da deficiência hídrica. Mediram-se o comprimento e a largura de todas as folhas de uma planta por repetição, e a área foliar foi obtida com resultado do produto de comprimento, largura e de um fator de forma (f), que, para E. grandis, foi estimado em 0,73 e, para o E. saligna, em 0,77. Estes fatores foram determinados a partir da amostragem de 150 folhas de cada espécie, provenientes de plantas cultivadas concomitantemente ao cultivo da E1. 
$\mathrm{Na}$ E1, foi determinada a eficiência de uso da água (EUA) (Hsiao \& Acevedo, 1974; Gonçalves \& Passos, 2000). Esse indicador fornece a quantidade de água, em litros, necessária para a produção de $1 \mathrm{~kg}$ de biomassa ( $\mathrm{L} \mathrm{kg}^{-1} \mathrm{de}_{2} \mathrm{O}$ na massa seca) (Silva et al., 2004). Para a determinação da EUA, foi selecionada uma repetição de cada tratamento antes da aplicação da deficiência hídrica, na qual foi determinada a biomassa seca total e de cada compartimento (raízes, folhas e caule), pesando-se o material levado à estufa a $65{ }^{\circ} \mathrm{C}$ até massa constante. Ao término do experimento, foi determinada a biomassa total e de cada compartimento em todas as plantas das repetições. A EUA foi calculada pela equação (Silva et al., 2004):

$$
\mathrm{EUA}=\frac{\text { Total de água transpirada em cada tratamento }}{\text { Biomassa final - biomassa inicial de cada tratamento }}
$$

As temperaturas mínimas e máximas diárias do ar foram medidas durante todo o período do experimento, com um termômetro de mínima de álcool e de um termômetro de máxima de mercúrio, respectivamente, instalados dentro de um miniabrigo meteorológico de madeira, pintado de branco e instalado na altura e ao lado da bancada onde estavam as plantas.

A deficiência hídrica foi imposta quando as plantas tinham em média 20 folhas acumuladas na HP, quando foi suprimida a reposição de água no tratamento com deficiência hídrica. O método utilizado para quantificar o déficit hídrico foi o de Sinclair \& Ludlow (1986), Muchow \& Sinclair (1991), Lecoeur \& Sinclair (1996), Ray \& Sinclair (1997), Bindi et al. (2005) e Sinclair et al. (2005). Para garantir que a água fosse perdida apenas através da transpiração das plantas, todos os vasos foram cobertos por um filme plástico branco, a fim de minimizar a perda de água pela evaporação do solo. Os vasos foram saturados com água, deixados drenar por $10 \mathrm{~h}$ para atingir a capacidade de campo e pesados para determinar a massa inicial. A partir de então, foi aplicada a deficiência hídrica nos vasos do T2, os quais não foram mais irrigados até o final do experimento. Diariamente, ao final da tarde, todos os vasos foram pesados. Logo após a pesagem, os vasos do T1 foram irrigados com a quantidade de água perdida pela transpiração das plantas, determinada pela diferença entre a massa do vaso no dia específico e a massa inicial (primeiro dia em que foi aplicada a deficiência hídrica). O término do experimento foi considerado quando as plantas do T2 atingiram uma taxa de transpiração relativa (TR) de $10 \%$, comparada com as plantas do T1, calculada pela equação (Sinclair \& Ludlow, 1986):

$$
\mathrm{TR}=\frac{\text { Perda diária de água das plantas do T2 (cada balde) }}{\text { Média diária da perda de água das plantas do T1 }}
$$

A TR foi normalizada para reduzir a variação que ocorreu entre as repetições e experimentos, procedimento usado em outros trabalhos (Sinclair \& Ludlow, 1986; Lecoeur \& Sinclair, 1996; Ray \& Sinclair, 1997). Essa variação deveu-se à diferença no crescimento das plantas na E1 e E2. A TR foi normalizada dividindo-se os valores individuais de TR pela média de todos os valores de TR quando a FATS foi maior que 0,50 (Sinclair \& Ludlow, 1986). A fração de água transpirável no solo (FATS) foi calculada pela equação (Sinclair \& Ludlow, 1986):

$$
\text { FATS }=\frac{\text { Massa de cada balde em cada dia }- \text { Massa final }}{\text { Massa inicial de cada repetição }- \text { Massa final }}
$$

A massa final é a massa do vaso quando a transpiração relativa (TR) atingiu 10\%. O limite de $10 \%$ foi usado por ter sido assumido que abaixo dessa taxa de transpiração os estômatos estão fechados e a perda de água é devida apenas à condutância epidérmica (Sinclair \& Ludlow, 1986).

As variáveis de crescimento $(h, d)$ e desenvolvimento (NF) foram normalizadas, para ficarem entre os intervalos de valores de 0 a 1, pela equação (Sinclair et al., 2005):

$$
\mathrm{Vn}=\frac{\text { valor } \mathrm{TR} 10 \%-\text { valor }(\mathrm{n})}{\text { valor } \mathrm{TR} 10 \%-\mathrm{v} \text { inicial }}
$$

em que Vn é variável normalizada ( $\mathrm{h} d, \mathrm{NF}$ ), valor TR $10 \%$ é o valor da variável quando a TR foi $10 \%$ (final do experimento), valor (n) é o valor da variável no dia específico e v inicial é o valor da variável no primeiro dia do experimento.

Os dados das variáveis Vn e TR (variável dependente - y) foram ajustados a uma função logística da variável FATS (variável independente $-\mathrm{x}$ ) (Bindi et al., 2005) do tipo:

$$
y=a /\left(1+\exp \left(b_{0} *\left(x-b_{1}\right)\right)\right)
$$

em que $a, b_{0}$ e $b_{1}$ são coeficientes estimados com o procedimento MODEL do SAS (SAS, 2001). As curvas ajustadas foram utilizadas para determinar, para as duas espécies de eucalipto, o valor de FATS em que se iniciou a redução da transpiração relativa e, conseqüentemente, da condutância estomática (transição entre o estádio I e estádio II da transpiração), bem como a FATS em que o crescimento e o desenvolvimento começaram a ser afetados (Sinclair \& Muchow, 2001). O critério utilizado para definir o valor da FATS em que se iniciou a redução do crescimento e desenvolvimento foi quando o valor da curva (valor das variáveis normalizadas TR, h, d e $\mathrm{NF}$ ) começou a decrescer a partir da unidade na curva logística (Sinclair \& Ludlow, 1986; Ray \& Sinclair, 1997). Para avaliar o ajuste das equações, foram utilizados os indicadores estatísticos eficiência do modelo $(E m)$ e erro-padrão de estimativa $\left(\mathrm{S}_{\mathrm{yx}}\right)$ (Schneider, 1998). As análises estatísticas foram realizadas utilizando o software SAS (SAS, 2001). 


\section{RESULTADOS E DISCUSSÃO}

Houve grande variação nas condições meteorológicas entre as duas épocas de semeadura do experimento. A temperatura mínima e a máxima absoluta do ar durante a época 1 (E1) foram de 9,4 e $43,4^{\circ} \mathrm{C}$, respectivamente. A média da temperatura mínima do ar foi de $17,1^{\circ} \mathrm{C}$, a média da temperatura média do ar (calculada pela média aritmética entre a temperatura mínima e máxima) foi de $25,1^{\circ} \mathrm{C}$ e a média da temperatura máxima do ar foi de $33,2^{\circ} \mathrm{C}$. Durante a época 2 (E2), a temperatura mínima e a máxima absoluta do ar ) foram de 2,0 e $38,9^{\circ} \mathrm{C}$, respectivamente. A média da temperatura mínima do ar foi de $12,8^{\circ} \mathrm{C}$, a média da temperatura média do ar foi de $19,8^{\circ} \mathrm{C}$ e a média da temperatura máxima do ar foi de $26,8^{\circ} \mathrm{C}$. Essas diferenças de condições meteorológicas nas duas épocas de semeadura causaram uma variação na demanda atmosférica transpirativa e, conseqüentemente, uma diferença na duração do período (dias) de deficiência hídrica até atingir 10 \%de TR. Na E1, a aplicação da deficiência hídrica teve início no dia 29/11/2005 e terminou dia 9/12/2005, totalizando 11 dias. A temperatura média do ar nesse período foi de $36,1^{\circ} \mathrm{C}$. Na E2, a aplicação da deficiência hídrica iniciou em 21/9/2006 e terminou em 11/10/2006, prolongando-se por 20 dias. Nesse período, a temperatura média do ar foi de $31,1^{\circ} \mathrm{C}$.

A transpiração e o consumo de água na planta são comandados pela demanda atmosférica e pelo controle estomático (Carlesso, 1995). A transpiração e o consumo de água das duas espécies estão apresentados no quadro 1.

O E. saligna teve maior transpiração e consumiu mais água diariamente que o E. grandis no T1, em ambas as épocas de semeadura (Quadro 2), o que está relacionado com a maior área foliar encontrada nesta espécie (Whitehead \& Breadle, 2004). No T2 da primeira época de semeadura, o Eucalyptus saligna apresentou transpiração e consumo de água similares aos de E. grandis, diferentemente da segunda época de semeadura no T2, quando o $E$. saligna teve uma transpiração e consumo de água menores do que os do E. grandis. Houve redução na transpiração e no consumo de água no T2, em ambas as espécies, graças à redução na área foliar, tendo sido essa redução na área foliar maior no E. grandis. No E. saligna, houve maior redução na transpiração e no consumo de água, apesar da menor redução na área foliar, pelo fato de tal espécie apresentar maior controle na abertura e fechamento estomático (Silva et al., 2004).

Os valores de EUA, calculados considerando todas as plantas e o total de água consumido por estas plantas, para $E$. grandis e $E$. saligna na época $E 1$ foram, respectivamente, de 282 e $275 \mathrm{~L} \mathrm{~kg}^{-1} \mathrm{de}_{2} \mathrm{O}$ de massa seca no T1 e de 241 e $228 \mathrm{~L} \mathrm{~kg}^{-1} \mathrm{de}_{2} \mathrm{O}$ de massa seca no T2. Esses resultados indicam que o $E$. saligna utiliza mais eficientemente a água do que o $E$. grandis, por apresentar menor valor de EUA em ambas as épocas estudadas. Os valores de EUA encontrados no presente estudo são menores que os valores encontrados por Balbino et al. (2003) em soja (700 $\mathrm{L} \mathrm{kg}^{-1}$ de $\mathrm{H}_{2} \mathrm{O}$ de massa seca) e milho (300$400 \mathrm{~L} \mathrm{~kg}^{-1} \mathrm{de}_{2} \mathrm{O}$ de massa seca) e por Singh et al. (2003) em sorgo (277 L kg-1 de $\mathrm{H}_{2} \mathrm{O}$ de massa seca), beterraba açucareira (443 $\mathrm{L} \mathrm{kg}^{-1}$ de $\mathrm{H}_{2} \mathrm{O}$ de massa seca), trigo de primavera (491 $\mathrm{L} \mathrm{kg}^{-1} \mathrm{de}_{2} \mathrm{O}$ de massa seca), cevada (527 $\mathrm{L} \mathrm{kg}^{-1} \mathrm{de}_{2} \mathrm{O}$ de massa seca), batata (575 $\mathrm{L} \mathrm{kg}^{-1} \mathrm{de}_{2} \mathrm{O}$ de massa seca) e aveia (583 $\mathrm{L} \mathrm{kg}^{-1}$ de $\mathrm{H}_{2} \mathrm{O}$ de massa seca).

As relações entre as variáveis normalizadas TR, h, d e NF com a FATS, nas duas épocas de semeadura, encontram-se nas figuras 1 e 2, respectivamente. Observou-se considerável variabilidade nos dados, especialmente nas variáveis TR e NF na época E2 (Figura 2), quando as temperaturas foram menores.

Quadro 1. Transpiração total média por planta e consumo médio de água em mudas de Eucalyptus grandis e Eucalyptus saligna, em dois tratamentos de manejo de água/irrigação (T1 e T2) e duas épocas de semeadura (E1 e E2), em casa de vegetação. Santa Maria, RS, 2005/2006

\begin{tabular}{|c|c|c|c|c|}
\hline \multirow[t]{2}{*}{ Variável } & \multicolumn{2}{|c|}{ E. grandis } & \multicolumn{2}{|c|}{ E.saligna } \\
\hline & T1 & T2 & $\mathbf{T} 1$ & T2 \\
\hline
\end{tabular}

E1
Transpiração (g/planta)
Consumo (mm planta dia ${ }^{-1}$ )
$1.825( \pm 78)$
5,81
$911( \pm 74)$
2,90
$2.008( \pm 99)$
6,39
$919( \pm 74)$
2,93
E2
Transpiração (g/planta)
Consumo(mm planta dia $\left.^{-1}\right)$
$1.744( \pm 33)$
$621( \pm 17)$
2,77
1,03
$1.923( \pm 50)$
3,05
$519( \pm 20)$
0,83

Valores entre parênteses correspondem ao desvio-padrão da média. T1: Sem deficiência hídrica, T2: Com deficiência hídrica, E1: Semeadura em 1/10/2005, E2: Semeadura em 12/5/2006. 
Quadro 2. Área foliar média inicial (AFi) e final (AFf) de mudas de Eucalyptus grandis e Eucalyptus saligna, em dois tratamentos de manejo da água/irrigação (T1 e T2) e duas épocas de semeadura (E1 e E2), em casa de vegetação. Santa Maria, RS, 2005/2006

\begin{tabular}{|c|c|c|c|c|}
\hline \multirow{2}{*}{ Variável } & \multicolumn{2}{|c|}{ E. grandis } & \multicolumn{2}{|c|}{ E.saligna } \\
\hline & $\mathbf{T} 1$ & T2 & T1 & T2 \\
\hline \multicolumn{5}{|c|}{$\mathrm{E} 1$} \\
\hline $\mathrm{AFi}\left(\mathrm{cm}^{2} /\right.$ planta $)$ & $146,86( \pm 24,3)$ & $240,87( \pm 91,5)$ & $232,75( \pm 75,7)$ & $205,71( \pm 82,9)$ \\
\hline $\operatorname{AFf}\left(\mathrm{cm}^{2} /\right.$ planta $)$ & $817,74( \pm 214,6)$ & $344,61( \pm 137,9)$ & $1.100,53( \pm 307,8)$ & $436,08( \pm 131,7)$ \\
\hline \multicolumn{5}{|c|}{$\mathrm{E} 2$} \\
\hline $\mathrm{AFi}\left(\mathrm{cm}^{2} /\right.$ planta $)$ & $309,42( \pm 101,8)$ & $216,58( \pm 46,7)$ & $360,09( \pm 80,7)$ & $279,45( \pm 50,5)$ \\
\hline $\operatorname{AFf}\left(\mathrm{cm}^{2} /\right.$ planta $)$ & $835,69( \pm 185,2)$ & $265,20( \pm 99,7)$ & $890,69( \pm 96,1)$ & $312,05( \pm 79,2)$ \\
\hline
\end{tabular}

Valores entre parênteses correspondem ao desvio-padrão da média. T1: Sem deficiência hídrica, T2: com deficiência hídrica, E1: Semeadura em 1/10/2005, E2: Semeadura em 12/5/2006.

Essa variabilidade também foi verificada em outros estudos, principalmente sob condições de baixas temperaturas (inferiores a $15^{\circ} \mathrm{C}$ ), quando a transpiração foi menor (Sinclair \& Ludlow, 1986). Apesar dessa variabilidade, houve tendência de decréscimo das variáveis, à medida que a FATS decresceu até zero, e esse decréscimo pode ser descrito por uma equação logística, como foi relatado em estudos com outras espécies (Sinclair \& Ludlow, 1986; Amir \& Sinclair, 1991; Lecoeur \& Sinclair, 1996; Ray \& Sinclair, 1997). Observou-se tendência similar de decréscimo das variáveis em ambas as épocas de semeadura, indicando uma resposta geral das variáveis à FATS. Todas as equações logísticas ajustadas para a TR de ambas as espécies, nas duas épocas de semeadura, apresentaram precisão aceitável, com valores elevados de Em e baixos de $\mathrm{S}_{\mathrm{yx}}$ e coeficientes significativos a $5 \%$.

Comparando a resposta das variáveis normalizadas à FATS, observaram-se semelhanças e diferenças entre as duas espécies. A TR na época E1 apresentou uma resposta similar entre as duas espécies, já que os valores dos coeficientes $b_{0}$ e $b_{1}$ foram similares (Figura 1). Seguindo o critério de Sinclair \& Ludlow (1986) de que o valor de FATS em que inicia a redução da TR (estádio I da transpiração) é quando a curva estimada pela equação logística afasta-se de 1,0 e inicia o decréscimo linear, o valor de FATS para as duas espécies na época E1 foi aproximadamente de 0,7. Já, na época E2, houve tendência de uma redução de TR a uma FATS maior no E. grandis do que no E. saligna (Figura 2), dado pelo valor maior (menos negativo) do coeficiente $\mathrm{b}_{0}$ no primeiro comparado com o segundo. Neste caso, a FATS em que se iniciou a redução de TR foi de, aproximadamente, 0,9, para E. grandis, e de 0,7 , para $E$. saligna. A partir desses valores de FATS, a TR começou a diminuir linearmente em ambas as espécies, nas duas épocas de semeadura. Os valores de FATS de 0,9 e 0,7 foram superiores aos de culturas agrícolas anuais, como os obtidos por
Sinclair \& Ludlow (1986) para soja (FATS $=0,40)$, guandu (FATS $=0,40)$, feijão mungo $($ FATS $=0,40)$ e feijão caupi (FATS = 0,30); por Amir \& Sinclair (1991) para trigo de primavera (FATS $=0,30)$; por Lecoeur $\&$ Sinclair (1996) para ervilha (FATS $=0,55$ ) e por Ray \& Sinclair (1997) para milho (FATS = 0,50). Também foram superiores a algumas espécies perenes como aos obtidos por Bindi et al. (2005) para videira (FATS =0,35); por Sinclair et al. (2005) para tuia (Thuja plicata FATS $=0,35)$, algarrobeira (Robinia pseudoacacia, FATS =0,30), Hibiscus sp. (FATS = 0,30), azevinho europeu (Ilex aquifolium, FATS = 0,30) e acer (Acer rubrum, FATS =0,25), por Gollan et al. (1985) para a espirradeira (Nerium olander L., FATS $=0,50)$.

O início da redução da transpiração é um indicativo do fechamento estomático e marca a transição entre o estádio I e II da transpiração (Sinclair \& Ludlow, 1986; Bindi et al., 2005). O valor de FATS em que ocorreu o início do fechamento estomático, encontrado para estas duas espécies, é considerado alto, o que pode ser visto como uma vantagem para estas duas espécies de eucalipto (Sinclair et al., 2005). O fechamento estomático em uma condição de umidade do solo mais alta resulta na conservação da água no solo e constitui uma adaptativa da espécie, característica possivelmente para melhor suportar a deficiência hídrica prolongada (Muchow \& Sinclair, 1991).

A similaridade da relação entre TR e a FATS e, conseqüentemente, dos estádios I e II da transpiração verificada entre as duas espécies de eucalipto na época E1 e entre as duas épocas no E. saligna, em que as plantas desidrataram em condições de temperatura (e demanda hídrica) diferente, reforça a teoria de que o fechamento estomático, para evitar ou reduzir a perda de água e a perda de turgor do tecido vegetal, é determinado pelo teor de água no solo (Sinclair \& Ludlow, 1986), apontando em favor de sinais nas raízes como os responsáveis pelo controle estomático (Steudle \& Peterson, 1998; Streck, 2004). 

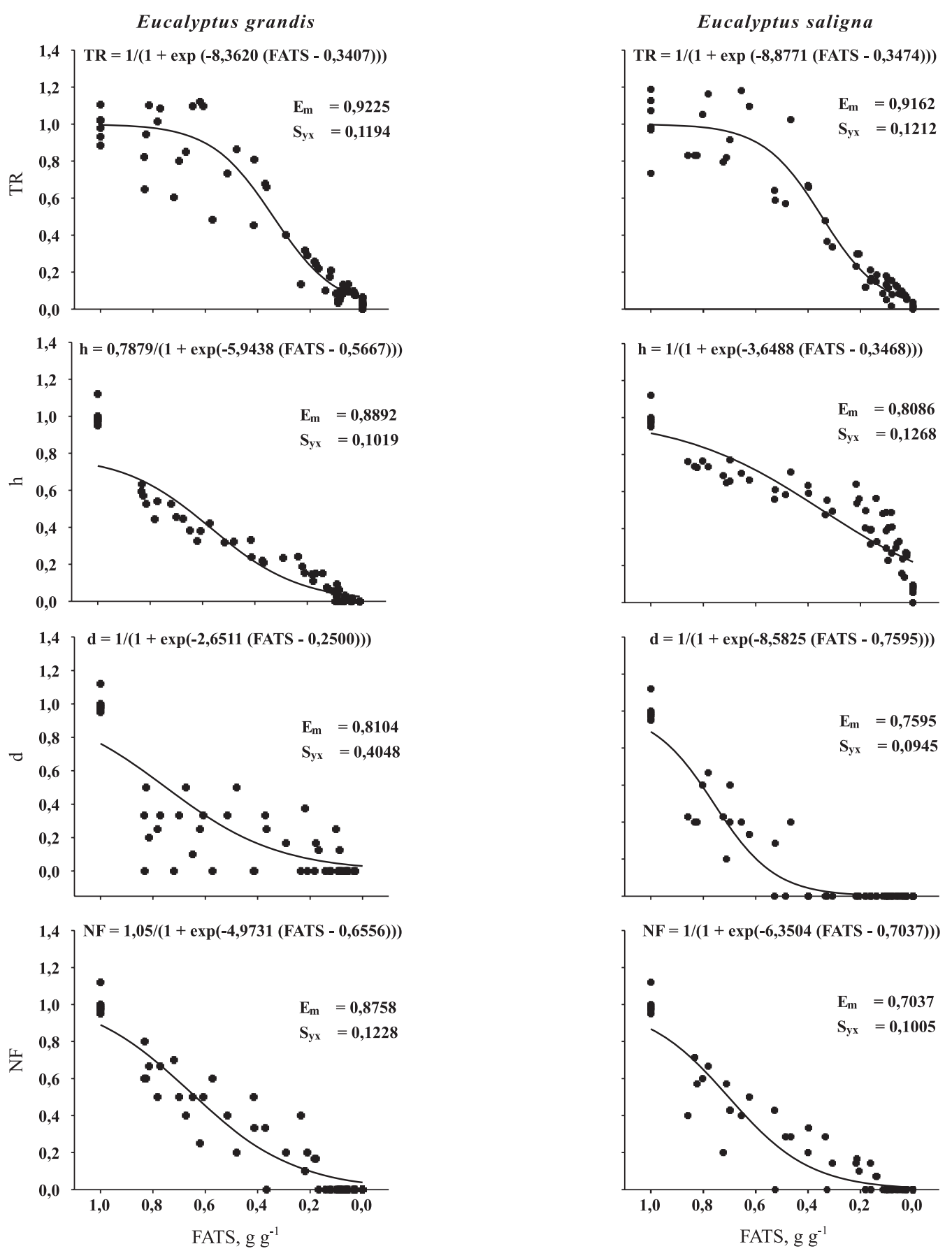

Figura 1. Valores normalizados de taxa de transpiração relativa (TR), altura de planta (h), diâmetro de caule (d) e número de folhas na haste principal (NF), em função da fração de água transpirável no solo (FATS), para mudas de Eucalyptus grandis e Eucalyptus saligna, cultivados em casa de vegetação na época de semeadura realizada em 1/10/2005 (E1). Santa Maria, RS, 2005. $\mathrm{E}_{\mathrm{m}}$ : Eficiência do modelo, $\mathrm{S}_{\mathrm{yx}}$ : Erro-padrão da estimativa.

Os valores normalizados de h, d e NF demonstram que estas variáveis começaram a ser afetadas imediatamente após o início da aplicação da deficiência hídrica, em ambas as espécies e épocas de semeadura, em resposta à redução da FATS (Figuras 1 e 2). Porém, em dias do calendário civil, os sintomas da deficiência hídrica (enrolamento e murchamento das folhas) apareceram em torno de cinco dias na época $\mathrm{E} 1$ e 10 dias na época $\mathrm{E} 2$. O fato de as variáveis $h$, d e NF terem sido afetadas pelo déficit hídrico no solo, antes mesmo que a transpiração, indica que deve ter ocorrido diminuição na turgescência das células antes do fechamento estomático, suficiente para afetar o metabolismo e 

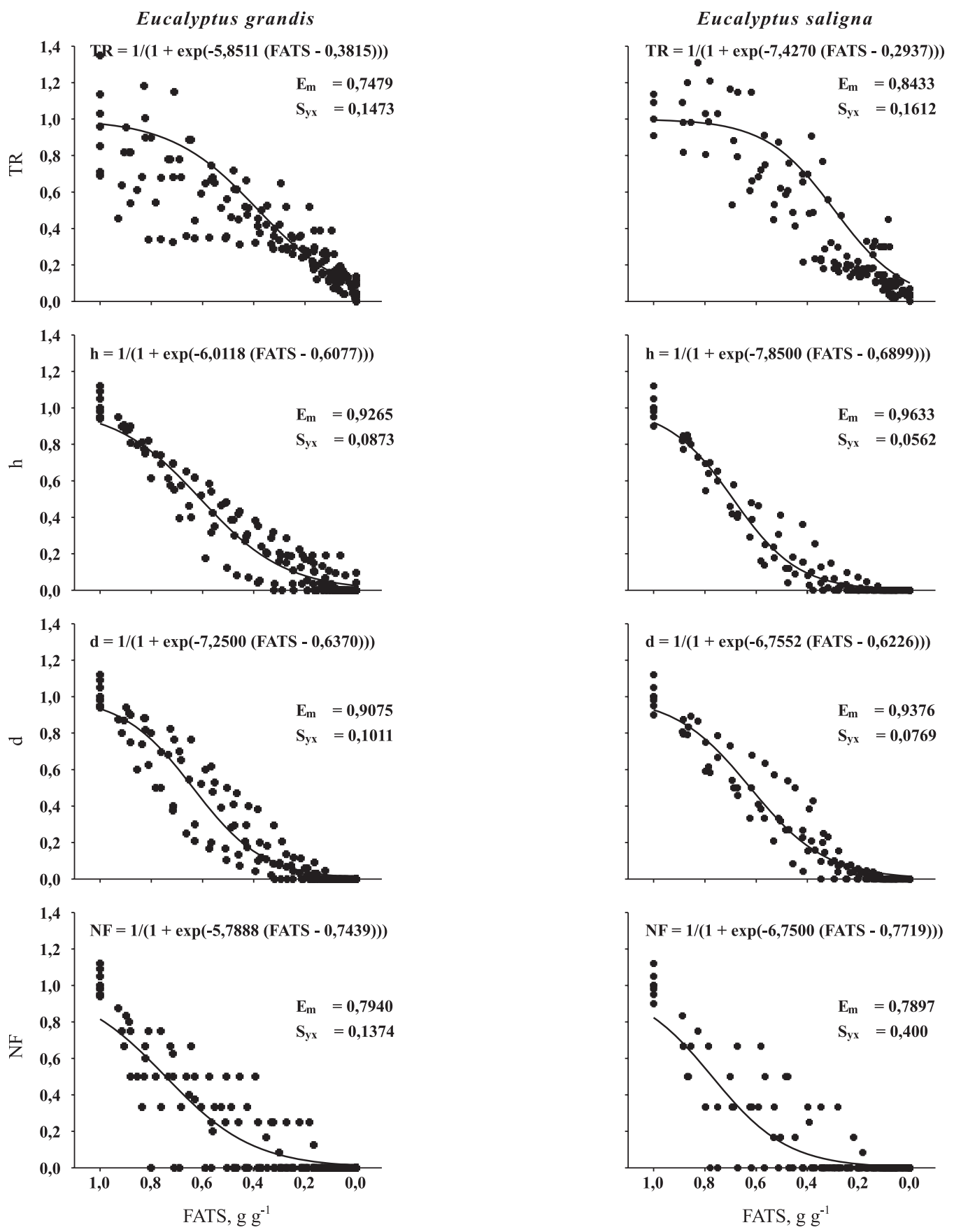

Figura 2. Valores normalizados de taxa de transpiração relativa (TR), altura de planta (h), diâmetro de caule (d) e número de folhas na haste principal (NF) em função da fração de água transpirável no solo (FATS) para mudas de Eucalyptus grandis e Eucalyptus saligna cultivados em casa de vegetação na época de semeadura realizada em 12/5/2006 (E2). Santa Maria, RS, 2006. $\mathrm{E}_{\mathrm{m}}$ : Eficiência do modelo, $\mathrm{S}_{\mathrm{yx}}$ : Erropadrão da estimativa.

causar redução no crescimento e desenvolvimento das mudas.

Nas épocas E1 e E2, o Eucalyptus saligna demorou, respectivamente, dois e cinco dias mais que o Eucalyptus grandis para apresentar os sintomas de deficiência hídrica nas variáveis de crescimento e desenvolvimento, indicando que $E$. saligna é mais tolerante à deficiência hídrica do que E. grandis. Tais resultados podem ser explicados pela tendência de ter ocorrido fechamento estomático mais tarde, em uma FATS menor, no E. saligna do que no E. grandis, especialmente na época E2 (Figura 2), mas também pode ter ocorrido na época $E 1$, já que o coeficiente $b_{0}$ foi menor no E. saligna (Figura 1). 
Os resultados deste estudo suportam a hipótese de que há diferença na resposta à deficiência hídrica no solo entre as diferentes plantas, como indicado por Sinclair et al. (2005). As espécies de eucalipto estudadas neste trabalho têm mecanismos de controle estomático para promover o decréscimo na taxa de transpiração em uma condição inicial de déficiência hídrica mais cedo, assim como uma redução no crescimento e desenvolvimento durante a deficiência hídrica, provavelmente como uma adaptação a condições de déficit hídrico (Bindi et al., 2005; Sinclair et al., 2005).

\section{CONCLUSÕES}

1. O crescimento e o desenvolvimento de mudas de eucalipto foram afetados pela deficiência hídrica, medido em FATS, antes mesmo de ser a transpiração afetada pela redução da água no solo.

2. O início da redução da transpiração, indicativo do início do fechamento estomático, mostrou-se dependente das condições climáticas e aumentou com a temperatura ambiente, iniciando quando a fração de água transpirável no solo situava-se entre 0,9 e 0,7 .

3. Os valores de FATS para as duas espécies de eucalipto foram maiores do que os da maioria das culturas anuais e perenes estudadas, indicando boa adaptação dessas espécies à deficiência hídrica no solo.

\section{AGRADECIMENTOS}

Ao CNPq, pelas bolsas concedidas a F.B. Martins (bolsa de Mestrado) e a N.A. Streck (bolsa de Produtividade em Pesquisa), e à CAPES, pela bolsa concedida a J.C. da Silva (bolsa de doutorado). Aos Revisores Ad Hoc, pelas valiosas contribuições e sugestões.

\section{LITERATURA CITADA}

ASSOCIAÇÃO BRASILEIRA DE FLORESTAS PLANTADAS - ABRAF. Anuário Estatístico da ABRAF: ano base 2005. Brasília, 2006. Disponível em: <http://www.ipef.br/ estatisticas/relatorios/anuario-ABRAF-2006.pdf>. Acesso em: 7 dez. de 2006.

AMIR, J. \& SINCLAIR, T.R. A model of water limitation on spring wheat growth and yield. Field Crops Res., 29:5996, 1991.

BALBINO, L.C.; BROSSARD, M.; STONE, L.F. \& LEPRUN, J.C. Estruturas e propriedades hidráulicas em latossolos sob cultivo na região do Cerrado. Rio de Janeiro, Embrapa, 2003. 44p. (Boletim de Pesquisa e Desenvolvimento, 8)
BINDI, M.; BELLESI, S.; ORLANDINI, S.; FIBBI, F.; MORIONDO, M. \& SINCLAIR, T. Influence of water deficit stress on leaf area development and transpiration of Sangiovese Grapevines grown in pots. Am. J. Enol. Vitic., 56:68-72, 2005.

CARLESSO, R. \& ZIMMERMANN, L.F. Água no solo: parâmetros para dimensionamento de sistemas de irrigação. Santa Maria, Imprensa Universitária, 2000. 88p.

CARLESSO, R. Absorção de água pelas plantas: água disponível versus água extraível e a produtividade das culturas. Ci. Rural, 25:183-188, 1995.

CARLESSO, R. \& SANTOS, R.F. Disponibilidade de água às plantas de milho em solos de diferentes texturas. R. Bras. Ci. Solo, 23:27-33, 1999.

FAÇANHA, J.G.V.; OLIVA, M.A.; LOPES, N.F. \& BARROS, N.F. Relação germinação/crescimento em espécies de eucalipto submetidas a estresse hídrico. R. Árvore, 7:177187,1983

GOLLAN, T.; TURNER, N.N. \& SCHULZE, E.D. The responses of stomata and leaf gas exchange to vapor pressure deficits and water content III. In the sclerophyllous woody species Nerium olander. Oecologia, 35:356-362, 1985.

GONÇALVES, M.R. \& PASSOS, C.A.M. Crescimento de cinco espécies de eucalipto submetidas a déficit hídrico em dois níveis de fósforo. Ci. Flor., 10:145-161, 2000.

HSIAO, T.C. \& ACEVEDO, E. Plant responses to water deficits, water-use efficiency, and drought resistance. Agric. Meteorol., 14:59-84, 1974.

JELLER, H. \& PEREZ, S.C.J.G.A. Efeitos dos estresses hídrico e salino e da ação da giberelina em sementes de Senna spectabilisi. Ci. Flor., 11:93-104, 2001.

KALLARACKAL, J. \& SOMEN, C.K. An ecophysiological evaluation of the suitability of Eucalyptus grandis for planting in the tropics. For. Ecol. Manag., 95:53-61, 1997.

LARCHER, W. Ecofisiologia vegetal. São Carlos, Rima, 2000. $215 p$.

LECOEUR, J. \& SINCLAIR, R.T. Field pea transpiration and leaf growth in response to soil water deficits. Crop Sci., 36:331-335, 1996

LEVIT, J. Responses of plants to environmental stresses. II. Water, radiation, salt and the other stress. New York, Academic Press, 1980. 606p.

LIMA, W.P. Impacto ambiental do eucalipto. 2.ed. São Paulo, Universidade de São Paulo, 1993. 301p.

MUCHOW, R.C. \& SINCLAIR, T.R. Water deficits effects on maize yields modeled under current and "greenhouse" climates. Agron. J., 83:1052-1059, 1991.

RAY, J.D. \& SINCLAIR, T.R. Stomatal conductance of maize hybrids in response to drying soil. Crop Sci., 37:803-807, 1997. 
SANTARÉM, E.R.; CORTEZ, J.S.A.; SILVEIRA, T.S. \& FERREIRA, A.G. Efeito do estresse hídrico na germinação e crescimento inicial de três espécies de leguminosas. Acta Bot. Bras., 10:213-221, 1996.

SANTOS, R.F. \& CARLESSO, R. Déficit hídrico e os processos morfológico e fisiológico das plantas. R. Bras. Eng. Agric. Amb., 2:287-294, 1998.

SAS Institute. The SAS-System for Windows. Cary, 2001.

SCHNEIDER, P.R. Análise de regressão aplicada à Engenharia Florestal. 2.ed. Santa Maria, UFSM/CEPEF, 1998. 236p.

SILVA, W.; SEDIYAMA, T.; SILVA, A.A. \& CARDOSO, A.A. Índice de consumo e eficiência do uso da água em eucalipto, submetido a diferentes teores de água em convivência com a braquiária. Floresta, 34:325-335, 2004.

SINCLAIR, T.R. Water and nitrogen limitations in soybean grain production I. Model Development. Field Crops Res., 15:125-141, 1986.

SINCLAIR, T.R. \& LUDLOW, M.M. Influence of soil water supply on the plant water balance of four tropical grain legumes. Aust. J. Plant Physiol., 13:319-340, 1986.

SINCLAIR, T.R. \& MUCHOW, R.C. System analysis of plant traits to increase grain yield on limited water supplies. Agron. J., 93:263-270, 2001.
SINCLAIR, T.R.; HOLBROOK, N.M. \& ZWIENIECKI, M.A. Daily transpiration rates of woody species on drying soil. Tree Physiol., 25:1469-1472, 2005.

SINGH, D.K.; BIRD, P.R. \& SAUL G.R. Maximising the use of soil water by herbaceous species in the high rainfall zone of southern Australia: A review. Aust. J. Agron. Res., 54:667-691, 2003.

SOCIEDADE BRASILEIRA DE CIÊNCIA DO SOLO. COMISSÃO DE QUÍMICA E FERTILIDADE DO SOLO SBSC/CQFS. Manual de adubação e calagem para os estados do Rio Grande do Sul e de Santa Catarina. 10.ed. Porto Alegre, 2004. 394p.

STEUdLE, E. \& PETERSON, C.A. How does water get through roots? J. Exper. Bot., 49:775-788, 1998.

STRECK, N.A. Do we know how plants sense a drying soil? Ci. Rural, 34:581-584, 2004.

TAIZ, L. \& ZEIGER, E. Fisiologia vegetal. 3.ed. Piracicaba, Artmed, 2004. 720p.

WHITEHEAD, D. \& BREADLE, C.L. Physiological regulation of productivity and water use in Eucalyptus: A review. For. Ecol. Manag., 193:113-140, 2004. 